\title{
24. \\ VLADAN DESNICA \\ U SRPSKIM ŠKOLSKIM PROGRAMIMA \\ I UDŽBENICIMA
}

\section{Jelena Đorđević}

UDK: 37.091.214(497.11)“196/201“:821.163.42Desnica, V.

Izvorni znanstveni članak

Sažetak: U radu se daje pogled na mesto Vladana Desnice i njegovog književnog dela - poglavito romana Proljeća Ivana Galeba - u školskim programima i udžbenicima u Srbiji od 1964. godine do danas. Ističe se da je Desnica od trenutka kada je uključen u školski program stekao status kanonizovanog pisca čije je književno delo valorizovano kao integralni deo književnoistorijske tradicije. Iako je u međuvremenu došlo do pomeranja na liniji nacionalne pripadnosti (od svrstavanja u korpus savremene hrvatske književnosti do atribuiranja Desnice kao modernog srpskog književnika), te do promena u teorijskom i metodološkom pristupu, Desničino delo ostalo je nezaobilazna lektira za generacije srpskih srednjoškolaca.

Ključne reči: Vladan Desnica, Proljeća Ivana Galeba, školski programi, književna istorija, književna teorija, metodika, metodologija

I.

1 risustvo nekoga pisca u školskim kurikulumima, lektiri i čitankama uvek ima višestruko značenje. Mario Valdes ističe da je i to prisustvo nekog književnika u obrazovnom sistemu deo borbe za identitet, te da se i time „stvaraju koncepti, simboli i predstave pripadanja“. ${ }^{1}$ Otuda mesto u nastavnim programima za književnike znači i čin pripadanja, ali i čin prihvatanja, i to u višestrukom ključu - ideološkom, nacionalnom, estetskom i kulturološkom. Posebno osetljiv slučaj uvek je predstavljalo uključenje nekog savremenog pisca, koji je, osim svog književnog dela, nosio i „teret“ javnoga delovanja, te i na taj način sebi uvećavao ili smanjivao šanse da bude uvršten u ono što se kolokvijalno naziva školska lektira. A uvrštavanje u nastavni program značilo je - to odmah treba da bude jasno - i jedan od presudnih činova kanonizacije određenoga autora. Sve ovo pokušaćemo da pokaže-

1 Mario Valdes, „Rethinking the History of Literary History“, Rethinking Literary History: A Dialogueon Theory (ur. Linda Hutcheon i Mario J. Valdes), Oxford - New York 2002., 92. 
mo na primeru mesta Vladana Desnice u nastavnim programima za završni razred srednje škole u Srbiji, od trenutka njegovog uvrštenja, 1964. godine, pa do danas.

Uprkos prestrukturiranju, brojnim izmenama i višekratnim reformama u sistemu gimnazijskog i uopšte srednjoškolskog školovanja u socijalističkoj Jugoslaviji u prve dve decenije nakon Drugog svetskog rata, nastavni planovi i programi, otkako su prihvaćeni u prvim godinama nakon oslobođenja, nisu trpeli gotovo nikakve promene. Tek dvadeset godina posle rata u Srbiji je došlo do temeljnih promena i modernizacije nastavnih planova i programa. Učinjeno je to na inicijativu prosvetnih radnika, ali i snažnim angažovanjem Republičkog sekretarijata za prosvetu SR Srbije, 1964. godine. Izmene u planovima za srpskohrvatski jezik i književnost išle su za tim da povećaju prisustvo savremenih jugoslovenskih pisaca u školskim programima, i posebno u školskoj lektiri. Suštinska i dalekosežna promena ogledala se u tome da je proučavanje književnosti XIX veka prebačeno iz trećeg u drugi razred gimnazije i tako je oslobođen prostor za uvođenje savremenih jugoslovenskih i svetskih pisaca u program za četvrti razred gimnazije. Na taj način, obrada pisaca dvadesetog veka nije se više - kao do tada - okončavala metodskom jedinicom „Književnost narodnooslobodilačkog rata i revolucije“, već je dodata široka jedinica pod nazivom „Savremena književnost jugoslovenskih naroda“. ${ }^{2}$ Obavezna lektira dopunjena je nizom pisaca koji su se tek afirmisali. Od srpskih pisaca to su bili, na primer, Antonije Isaković i Vasko Popa, od slovenačkih Matej Bor. A od hrvatskih pisaca u lektiru su ušla trojica: Ranko Marinković bio je zastupljen pripovetkama Zagrljaj, Cvrčci i bubnjevi i Andeo; Vjekoslav Kaleb u novelama Na kamenu i Gost; kao treći tada je, prvi put - dakle u školskoj 1964./1965. godini - u školske programe u Srbiji uveden i Vladan Desnica (kao hrvatski pisac) svojim romanom Proljeća Ivana Galeba.

Mora se reći da ove izmene nisu učinjene nasumice. Naime, svako od navedenih književnih imena, i - još pre - svako novo književno delo, uneseno je u lektiru kao primer za određeni književni postupak, i povezano s proučavanjem teorije književnosti. U tom smislu, Desničin roman uzet je za primer romana-eseja, i kao takav proučavan na časovima. U planu i programu za četvrti razred gimnazije za roman-esej predviđena su bila tri časa. Prvi čas bio je posvećen samom teorijskom pojmu, njegovom objašnjenju i književnoistorijskom pristupu. Sledeća dva časa bila su predviđena za analizu Desničinog romana. ${ }^{3}$

No, ako je Desnica svojim romanom tada uvršten u obaveznu lektiru, ipak ni on, kao ni svi drugi pomenuti pisci, još nekoliko godina neće dobiti metodički pristup u čitankama, tj. neće biti odlomaka iz njihovih dela niti tumačenja i istraživačkih zadataka za učenike. Autori čitanke - Radmilo Dimitrijević i Dimitrije Vučenov - uneli su 1967. godine, u osmo izdanje svoje čitanke, samo biobibliografske beleške o ovim piscima. ${ }^{4} \mathrm{U}$ deveto izdanje, pak, uvrštena je Desničina novela Posjeta. ${ }^{5}$ Tek nakon nove izmene programa za srpskohrvatski jezik i književnost, 1974. godine, savremeni jugoslovenski pisci dobili su

\footnotetext{
V. Nastavni plan i program za gimnaziju u Socijalističkoj Republici Srbiji 1964/65, Beograd 1965., 17.

Prosvetni glasnik (Beograd), 15/1965., br. 1-2, 41.

4 Radmilo Dimitrijević i Dimitrije Vučenov, Čitanka za IV razred gimnazije sa teorijom književnosti, 8. izd., Beograd 1967., 288.

5 Isтi, Čitanka za IV razred gimnazije sa teorijom književnosti, 9. izd., Beograd 1969., 287-289.
} 
mesto i u čitankama, sa odlomcima svojih romana (ili čitavim pripovetkama i pesmama) i s određenim teorijsko-metodološkim aparatom. Suštinu ovih promena predstavlja zvanično usvojeni Nastavni program iz srpskohrvatskog jezika i književnosti za IV razred gimnazije, koji su autori, u originalnom obliku, doneli u uvodu svojoj čitanci. Ovaj program predstavlja u svojoj suštini povratak izrazito ideološkom pristupu nastavi srpskohrvatskog jezika i književnosti, i sasvim je u skladu s obnovljenim talasom dogmatizovanog uticaja Saveza komunista na javni život, koji se pre svega ispoljavao u kulturi i obrazovanju:

Imajući u vidu neophodnost da se pre donošenja novog zakona o srednjem obrazovanju, a to znači i pre izrade novih nastavnih programa za srednje škole, izvrši prethodno rasterećenje programa od manje važnih (tzv. sekundarnih, informativnih) tema i sadržaja, kao i aktuelnu potrebu za osavremenjivanjem društveno-političkih kretanja u našoj zemlji, u vezi sa nastavom srpskohrvatskog jezika u gimnaziji, dostavlja vam se orijentaciono uputstvo o sažimanju programskih sadržaja, racionalizaciji nastavnog procesa i idejno-estetskoj aktuelizaciji i usmerenosti ka daljem produbljivanju i bogaćenju socijalističkih odnosa i shvatanja u oblasti kulture i književnosti naroda i narodnosti Jugoslavije. ${ }^{6}$

Iza ovih floskula krili su se konkretni potezi kada je u pitanju nastavni plan za četvrti razred gimnazije. Iz programa su, tako, potpuno izbačeni Isidora Sekulić, Dušan Vasiljev, Mirko Božić i Karel Destovnik Kajuh. Izostavljeni su Andrićeva pripovetka Put Alije Đerzeleza i roman Travnička hronika, kao i Koreni Dobrice Ćosića, a takođe i romani sa ratnom tematikom, poput Hajke Mihaila Lalića ili Proloma Branka Ćopića. Nema sumnje da su u izostavljanju ovih dvaju dela prvenstvenu ulogu igrali ideološki momenti. Posebno je značajno uputstvo da se svi međuratni pravci u jugoslovenskim književnostima - od ekspresionizma, preko nadrealizma i modernizma, do socijalne književnosti - ,imaju proučavati u vezi sa uticajem Komunističke partije i marksističke ideologije na ideološko pregrupisavanje snaga u književnosti i kulturnom životu“?

U takvoj novoj ideološko-estetskoj klimi mesto Vladana Desnice ipak nije došlo u pitanje. Međutim, u biografskoj belešci autori čitanke su, sasvim nekritički, a očigledno vođeni navedenim uputstvima, istakli da se Desnica „kao književni stvaralac javio tek posle pobede narodnooslobodilačkog pokreta i završetka Drugog svetskog rata". ${ }^{8}$ Iz nastavnog programa, pa i iz čitanke, uklonjena je Posjeta, ali su zato Proljeća Ivana Galeba ostala u lektiri, a autori su u čitanku uneli odlomak iz romana, i to 57., 58. i 59. poglavlje. ${ }^{9}$ U prilogu su doneli i odlomak iz studije Dragana Jeremića $O$ književnom delu Vladana Desnice. ${ }^{10}$ Prvi put su autori, kada je reč o Desnici, odlomak propratili i metodološkim pitanjima za učenike:

Ako ste ranije čitali Desničine novele u zbirkama Zimsko ljetovanje, Proljeće u Badrovcu ili u zbirci Olupine na suncu, mogli ste lako uočiti izvesne njegove pripovedačke karakteristike. Koje su mu glavne odlike? Pokušajte ih formulisati - to nije teško za ovog izvrsnog pisca, i obrazložite ih svojim impresijama i sudovima. Zabeležite impresije i sudove o Desnici pri-

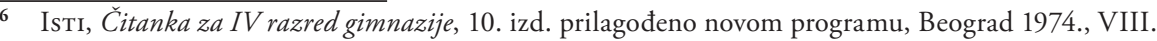

7 Isto, IX.

8 Isto, 330.

9 Isto, 330-338.

10 Isto, 339-341. 
povedaču, izrečene u odlomku iz ovog eseja [misli se na Jeremićev tekst; prim. J. Đ.]. Da li se vaše impresije i osećanja slažu sa ovim ovde izrečenim? Proverite ih. Šta mislite o Desnici kao piscu sada, kada ste pročitali roman Proljeća Ivana Galeba? Da li vam se dopada taj roman? Jeste li ga čitali lako i sa interesovanjem? To nije klasični realistički roman. Nazivaju ga romanom-esejom. Po kojim to specifičnim odlikama? Nađite ta esejistički formulisana piščeva razmatranja i razmišljanja. Ima ih i u ovome odlomku ponegde, a u romanu kao celini na mnogo mesta. Iz kakve to potrebe? Objasnite konkretnim podacima iz dela. ${ }^{11}$

Naravno, nije teško uočiti da su, sa metodološkog stanovišta, ovo krajnje uopštena i neprecizna pitanja, koja učenike ne mogu uputiti u ozbiljniju analizu Desničinog romana. Još neshvatljivije je da autori čitanke Zimsko ljetovanje proglašavaju za zbirku novela! Međutim, mnogo je značajnija eksplicitna tvrdnja Radmila Dimitrijevića i Dimitrija Vučenova koja Desnicu zapravo uvrštava u kanon tadašnje jugoslovenske književnosti, i to uz bok neprikosnovenim klasicima: „Vladan Desnica je, posle Ive Andrića i Miroslava Krleže, najznačajniji naš pisac, vrlo bogate i široke književne kulture." ${ }^{\text {"12 }}$

Desničino delo, međutim, i dalje je posmatrano prvenstveno kao izraziti primer romana-eseja, pa su autori u teorijskom dodatku čitanke, posle kratkog uvoda u istoriju samoga teorijskog pojma, taj pojam objašnjavali zapravo na primeru Desničinog romana. U Desničinom romanu oni su pronašli dokaze za tvrdnju da je roman-esej prevashodno roman iskustva, zatim da je to „roman ličnosti, a ne roman radnje“, a da je stil „izrazitije intelektualan nego emocionalan, isto onako kao i u eseju“. Iako elemente romana-eseja vide još i u Krležinom delu Povratak Filipa Latinovicza, a neke elemente i u novelama Ranka Marinkovića, autori čitanke naglašavaju da je „prvi pravi roman-esej dao Vladan Desnica“. ${ }^{13}$

Tako je mesto Vladana Desnice u nastavnim programima srpskohrvatskog jezika i književnosti u završnom razredu srednje škole - i to ne samo gimnazije već i srednjih stručnih škola - postalo neupitno i podrazumevajuće.

Recenzent čitanke Radmila Dimitrijevića i Dimitrija Vučenova, profesor Filološkog fakulteta u Beogradu Tode Čolak, i sam je bio autor čitanke za četvrti razred srednjeg usmerenog obrazovanja. Delo Vladana Desnice, roman Proljeća Ivana Galeba, i dalje je bilo deo obavezne lektire za taj razred, ali u Čolakovoj čitanci ono nije našlo mesta. Međutim, kako je udžbenike reformisanog programa pratila Teorija književnosti Dragiše Živkovića, u izdanju iz 1967. godine ${ }^{14}$ Živković je svoje teorijske postavke na više mesta ilustrovao primerima iz Desničinog romana Proljeća Ivana Galeba.

Govoreći, u uvodu, o vrstama umetnosti i o književnosti kao posebnoj umetničkoj vrsti, kao i o nastajanju umetničkog dela, Živković je svoje stavove potkrepio odlomcima iz Desničinog romana, kao i iz Pavletićevog razgovora sa Desnicom o nastanku književnog dela.

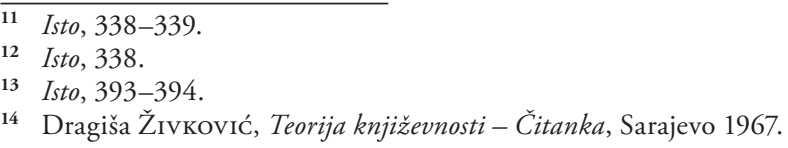


Insistirajući na temporalnosti kao važnoj poetičkoj kategoriji, Živković je iz tog razgovora naveo Desničinu tvrdnju „da je 1936. počeo da piše roman, ali da ga je menjao, dorađivao, prerađivao tokom dugog vremenskog perioda". 15

Živković je, najzad, primere iz Desničinog romana uzimao i za poglavlje o rađanju muzike i prepletenosti muzike i književnosti. To je potkrepio odlomkom u kome Ivan Galeb na tavanu stare porodične kuće nalazi violinu. Međutim, na tome mestu Živković se upušta i u stilsku analizu Desničinog romana Proljeća Ivana Galeba - govori o preobražaju, transformaciji i višeznačnosti jezika i stila pisca, ukazujući na bogatu paletu stilskih figura $\mathrm{u}$ analiziranom delu.

\section{3.}

Nastavni plan i program objavljen u Prosvetnom glasniku, br. 5 za 1990. godinu korigovao je dotadašnji program izučavanja jugoslovenskih književnosti, ali ne u bitnijem obimu. Program jeste skraćen, ali do drastičnijih izmena nije došlo. Nastavni program za četvrti razred gimnazija i srednjih stručnih škola zadržao je odrednicu „Savremena književnost“, i to kroz program obavezne lektire i kulture izražavanja. U okviru oblasti „Proučavanje književnog dela" bio je zastupljen i analizi podvrgnut i roman Vladana Desnice Proljeća Ivana Galeba.

Nova čitanka za četvrti razred gimnazija i srednjih stručnih škola, autorki Ljiljane Nikolić i Bosiljke Milić, ${ }^{16}$ odobrena je od Ministarstva prosvete 26. juna 1989. godine, i upotrebljavala se u nastavi od školske 1989./1990. godine. Za obradu Proljeća Ivana Galeba planirana su dva časa, a u čitanci se našao odlomak iz trideset prvoga poglavlja, tj. dijalog Ivana Galeba i župnika. Istraživački zadaci su bili krajnje uopšteni i fokusirani na analizu teksta Dragana Stojanovića, a on je pažnju posvetio pretežno zvukovnim osobenostima i višeznačnosti ovoga Desničinog romana. Desničin tekst tako je poslužio zapravo kao primer fenomenološkog pristupa analizi književnog dela. Autorke su učenicima ponudile i odlomak iz kritike Stanka Koraća, kao i poduži spisak sekundarne literature o delu Vladana Desnice. I dalje je fokus bio na osobinama Desničinog romana kao romana-eseja, što su autorke istakle i u uputstvu učenicima za proučavanje dela: „Proljeća Ivana Galeba je moderan roman-esej ostvaren pripovedanjem u prvom licu.“ To su potom potvrdile i u „Rečniku književnoteorijskih pojmova“, na kraju čitanke, ali tu su, međutim, Desničin roman uzele i za primer romana lika.

Iste te 1989. godine odobren je i mnogo zanimljiviji i kreativniji udžbenik pod nazivom Književnost i jezik, namenjen učenicima vojnih gimnazija i srednjih vojnih škola. Autori su bili Dragutin Rosandić, Milka Canić i Milivoje Minović. ${ }^{17}$ U ovom udžbeniku Desnica je određen kao posleratni hrvatski pisac, ${ }^{18}$ a analiza romana Proljeća Ivana Galeba uklopila

15 Isto, 39.

16 Ljiljana Nikolıć i Bosiljka Milıć, Čitanka sa književnoteorijskim pojmovima za IV razred srednje škole, Beograd 1989.

17 Dragutin Rosandić, Milka Canıć i Milivoje Minović, Književnost i jezik. Udžbenik za vojne gimnazije i srednje vojne škole, Beograd 1989.

18 Isto, 283. 
se u širi koncept tumačenja onih književnih dela koja govore o umetnosti, umetničkom procesu, i u kojima su dominantni likovi umetnika. U ovom udžbeniku puna pažnja poklonjena je Desničinim implicitnim poetičkim stavovima, a posebno plediranju za tzv. intelektualistički pristup književnom stvaralaštvu. U udžbenik je uneta 46. glava romana i izdvojene teme koje se u toj glavi ističu: smrt umetnika, problem umetničke sujete i ekshibicije, kao i razmatranje o tome ko se može smatrati istinskim umetnikom. Ukazano je na ključne motive u romanu Proljeća Ivana Galeba, potom su oni i grupisani: umetnost, smrt, detinjstvo, ljubav, prijateljstvo, lepota, samoća, nostalgija, religija, filozofija, pejzaž. Autori udžbenika su kroz istraživačka pitanja i zadatke upućivali na specifičnu formu romana. Nisu se, kao autori prethodnih čitanki, zadržali samo na definisanju Desničinog romana kao romana-eseja, već su istakli sve njegove segmente - oblik, tok, funkciju naratora, fabulu, jezik. Tome je poslužila i komparativna analiza Desničinog romana koja se zasnivala na njegovom poređenju sa delima Tomasa Mana i Oldosa Hakslija, kao i pozivanju na Prustov romaneskni ciklus:

Desničin roman „Proljeća Ivana Galeba“ ima fakturu modernog romana. Obrazložite tu tvrdnju. Možemo li taj roman nazvati „roman-esej“? Obrazložite. Koji su svjetski pisci stvarali takav tip romana, „romana-esej““? Koje romane Thomasa Manna i Aldousa Huxleya poznajete? Kojim se značajkama „Proljeća Ivana Galeba“ vežu uz manovski i hakslijevski tip romana? Desničin je tip romana - roman uspomena i sjećanja, roman povratka djetinjstvu. Koji je evropski pisac ostvario ciklus romana posvećen oživljavanju „izgubljena vremena"? 19

Autori su učenicima ponudili i tvrdnje koje bi trebalo da provere čitajući i analizirajući Desničin roman:

Desničin je roman pisan esejistički. Pojedini odlomci u romanu djeluju kao pjesma u prozi. U romanu se često javljaju lirske i meditativne digresije. Pripovedač ne razvija fabulu, tj. fabula nije primarni element romaneskne strukture. Desničin jezik nosi obilježja lirske poezije (višeznačnost, emocionalnost, slikovitost). Stvarnost prikazana u romanu reflektira se samo kroz pripovjedačevu (Galebovu) subjektivnost. Lik pripovjedača vremenski je distanciran, tj. iz udaljene relacije promatra događaje, ličnosti i doživljaje: to mu omogućuje analitički pristup. Pripovjedač se iskazuje u izravnim unutrašnjim monolozima. ${ }^{20}$

U tom segmentu pristupa Desničinom književnom delu učenici su pozvani da čitaju, kao dopunsku lektiru, pre svega Desničine novele, i da ih uporede sa njihovim verzijama koje su ušle u Proljeća Ivana Galeba. Takođe se u ovom udžbeniku prvi put našla i jedna Desničina pesma, iz zbirke Slijepac na žalu. Reč je o pesmi Podnevni ispit, koja je autorima poslužila kao primer karakterističnog Desničinog stila i transponovanja poetskog teksta iz jedne u drugu formu.

Desnica je u ovom udžbeniku predstavljen i u poglavlju „Književni portreti“. ${ }^{21} \mathrm{Tu}$ je, pored biografsko-bibliografske beleške, dat i kratak osvrt na Desničin roman Zimsko ljetovanje, pri čemu je kao osnovni kvalitet ovog Desničinog dela istaknuto to što je Desnica „izbegao folklorizam i spoljašnji opis koji ostaje u pozadini, a u prvi se plan nameću psi-

\footnotetext{
19 Isto, 281.

20 Isto, 281.

21 Isto, 388-389.
} 
hološke celine, zapravo tragedije čoveka zaostale dalmatinske sredine“, te da takvo viđenje sela „nismo dotada imali u našoj književnosti“. ${ }^{22}$

Od raspada Jugoslavije do danas Desničino mesto u obaveznoj lektiri u okviru školskog programa Republike Srbije je neupitno. Naravno, on se više ne svrstava u posleratne hrvatske pisce, ali se mora reći i to da se u tekstovima o njemu u čitankama i udžbenicima gotovo uopšte ne insistira na nacionalnom određenju (potrebe za ovakvim eksplikacijama i nije bilo s obzirom da se, u skladu s univerzitetskim planom i programom za studije književnosti, u svim čitankama i udžbenicima Vladan Desnica svrstava u savremenu srpsku književnost). To čini jedino Duško Babić - u svom udžbeniku za četvrti razred srednje škole on naglašava da je Desnica „srpski pisac“. ${ }^{23}$ Inače, Babićev udžbenik nije akreditovan od Ministarstva prosvete, ali se koristi kao pomoćna literatura. U njemu je izdvojena trideset prva glava Desničinog romana Proljeća Ivana Galeba, a donosi se i već pomenuti tekst Dragana Stojanovića. Dakle, pristup Desničinom književnom delu u suštini je isti kao i onaj Ljiljane Nikolić i Bosiljke Milić, što znači da se insistira na fenomenološkoj metodi. Takođe se najviše prostora daje analizi veze smrti i umetnosti, što je potvrđeno i odlomkom iz studije Radivoja Mikića, u kojoj on naglašava Desničin odnos prema vremenu i prolaznosti čoveka i njegovog sećanja. ${ }^{24}$

Udžbenik Petra Pijanovića ${ }^{25}$ specifičan je slučaj u metodičkom pristupu Desnici i njegovom delu, prevashodno zato što nije koncipiran kao čitanka. Dakle, Pijanović u svoj udžbenik ne unosi odlomke iz analiziranih dela, već daje biobibliografske podatke o pojedinim autorima. Kad je reč o Desnici, to je jedini slučaj u novijoj praksi da je neki autor udžbenika pre analize dela iz lektire, tj. Proljeća Ivana Galeba, učenicima pružio širi pogled na celokupan Desničin književni opus, ${ }^{26} s$ jasnim obrazloženjem da je Desničin opus ,intertekstualno umrežen i osmišljen “. ${ }^{27}$ Pijanović je tematski razvrstao celokupnu Desničinu prozu, i istakao da već u novelama „pripovedač nije toliko usredsređen na opis događaja koliko na unutarnju sliku i intimnu istinu", 28 što će postati osnovna karakteristika naracije u Proljećima Ivana Galeba. Tek posle ovoga uvida u Desničin književni opus, autor je ponudio konciznu analizu Desničinog glavnog dela ${ }^{29}$ insistirajući na konceptu naracije: ona je „necelovita i rasplinuta - dekomponovana u vremenu i decentrirana u prostoru romana“. ${ }^{30}$ Ovakav, dosledniji književnoteorijski pristup analizi Proljeća Ivana Galeba omogućen je većom metodičkom slobodom, tj. činjenicom da autor nije morao da prati metodička

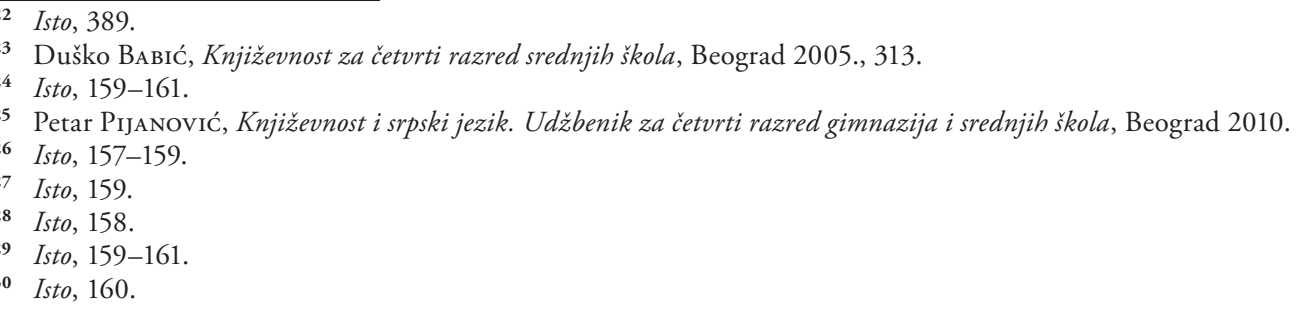


pravila koja važe za čitanke, već je učenicima pružio svoje viđenje najvažnijih elemenata Desničinog romana. Svodeći, u svom udžbeniku, metodička uputstva i pitanja za učenike na najosnovnija, ${ }^{31}$ on je mnogo detaljnije govorio o temi i narativnom postupku u Desničinom romanu, te vidovima modernog romana koji se u Proljećima Ivana Galeba mogu prepoznati (pored dotad već uočenog romana-eseja, još i roman o umetniku, roman lika, kao i monološko-asocijativni roman). ${ }^{32}$

Dve najnovije čitanke za četvrti razred srednjih škola, dva različita izdavača - izdavačke kuće Klett ${ }^{33}$ i izdavačke kuće $\operatorname{Logos}^{34}$ - nude zanimljiv materijal za uporednu analizu metodičkog pristupa romanu Proljeća Ivana Galeba. Autori i jedne i druge čitanke odlučili su se da u svoje čitanke unesu takođe trideset prvu glavu Proljeća Ivana Galeba, ali su analizi pristupili detaljnije i sa više teorijske širine. Doduše, autori Klettove čitanke odlomak Desničinog romana takođe su propratili tekstom Dragana Stojanovića, insistirajući pritom da učenici i u drugim delovima Desničinog romana pronađu primere za „intencionalnu snagu zvuka reči“, kao i da obrate pažnju na primere dvosmislenosti i višeznačnosti, u skladu $s$ Ingardenovim pojmom opalizacije. ${ }^{35} \mathrm{~S}$ druge strane, autori Logosove čitanke poslužili su se tekstom Nikole Miloševića „Duh modernog vremena u Proljećima Ivana Galeba“, koji je zasnovan na analizi odnosa umetnosti i stvarnosti, kao i na izdvajanju najvažnijih elemenata narativne strukture Desničinog romana. ${ }^{36}$ Iz ovoga sledi da je pristup autora Klettove čitanke zasnovan više na psihologiji (što se potvrđuje i zadacima za učenike - upućuju se da pročitaju i Frojdovo delo Psihopatologija svakodnevnog života), dok je pristup autora Logosove čitanke usredsređen na književnoteorijske postulate i naratološku analizu.

Tok analize autora Klettove čitanke zasnovan je na pet glavnih tačaka, formulisanih kao: „blagodat zaborava i okrutnost pamćenja“, „umetnost nas uči gledati na prirodu“, „podmukla igra neprepoznavanja“, „tupi, mučni zvuk pada“, tiranija „nehotične memorije“. ${ }^{37}$ Prva tačka analize učenicima zapravo skreće pažnju na literarne detalje u Desničinom romanu i asocijativnu mrežu u monolozima Ivana Galeba, ukazujući na to kako se „misaoni monološki sadržaji povezuju u harmoničnu celinu“ ${ }^{38}$ Druga tačka prilično sažeto i bez dubljih sagledavanja ukazuje na odnos stvarnosti i umetničkog pristupa zbilji. Tu se učenici upućuju da iskažu uglavnom sopstvene stavove o ovom problemu, i da ih obrazlože. Kako smo već pokazali, ovo pitanje nije pomnije istraženo zbog toga što se analiza autora čitanke zasniva pre svega na psihološkoj metodi. Treća tačka predstavlja analizu župnikovog lika, i ukazuje

31 „Koje novine unosi Vladan Desnica u srpsku prozu? Čime je zaokupljen njegov junak Ivan Galeb na kraju života? Kako je postavljeno vreme pripovedanja u Proljećima Ivana Galeba - hronološki ili na drugi način i zašto? Kojim umetničkim sredstvima je u ovom romanu predstavljen portret mislećeg junaka - umetnika u starosti? Utvrdite kojim bi odlikama roman Proljeća Ivana Galeba mogao da pripada različitim vidovima modernog romana." - isto, 162.

32 Isto.

33 Ljiljana BAJIĆ, Miodrag Pavlović i Zona Mrkalj, Čitanka za četurti razred gimnazije i srednjih stručnih škola, Beograd 2016.

34 Predrag Petrović, Mina Đurić, Boško Suvajdžıć i Nataša Stanković Šošo, Čitanka za četvrti razred gimnazije i srednjih stručnih škola, Beograd 2016.

35 Lj. Bajić, M. Pavlović i Z. Mrkalj, Čitanka za četurti razred, 129.

36 P. Petrović, M. Đurić, B. Suvajdžić i N. Stanković Šošo, Čitanka za četurti razred, 96.

37 Lj. Bajić, M. Pavlović i Z. Mrkalj, Čitanka za četvrti razred, 128-129.

38 Isto, 128. 
na mimikriju kao privid realnosti, usled čega dolazi do tragičnih nesporazuma. Posebno detaljno autori su obrazložili poslednje dve tačke analize. Četvrta tačka skreće pažnju na portret dedine majke i na psihološke efekte koje on ima ne samo na starca, već i na ljude iz njegove okoline. Učenici se upućuju da uoče kako odrasli u svojim „igrama“ pokazuju ogoljenu surovost, za razliku od dece. Konačno, u petoj tački govori se o „tiraniji sećanja“, o njegovoj snazi ali i opterećenju, zbog čega se „Galeb trajno seća jedne tričarije iz prošlosti, više od bitnijih detalja iz života ili svakodnevice“. 39

Nakon ove analize autori su zadatke za učenike logično usmerili u pravcu uočavanja psihologije glavnog junaka Desničinog romana, i na to da sami promisle o mehanizmima sopstvenog sećanja i pamćenja, i o značaju toga fenomena u ljudskom životu:

Na kakva razmišljanja te podstiče čitanje odlomka iz Desničinog romana? Koji su Galebovi stavovi zanimljivi? Zašto? Poseduješ li ti nehotičnu memoriju? Otkrij u kojim se životnim okolnostima ona javlja. Čime objašnjavaš fenomen sećanja na beznačajne pojedinosti iz svoje prošlosti? Otkrivaj u razgovoru na času u kojoj meri te pojedinosti možda govore nešto važno o tebi, tvojoj ličnosti ili tvom životu. Razmeni iskustva sa drugima. Svoja razmišljanja možeš i zabeležiti u formi eseja na temu „Čega se uvek sećam““40

S druge strane, autori Logosove čitanke nude nešto uopštenije istraživačke zadatke, ali pažnju usmeravaju prevashodno na problem odnosa umetnosti i stvarnosti, referirajući se na esej Nikole Miloševića. Posebno se insistira na odnosu naratora prema prošlosti, te na problemu identifikacije naratora (Ivana Galeba) i autora (Vladana Desnice):

Razmisli o tome mogu li u književnom tekstu autobiografske činjenice imati određenu vrednost ako nisu umetnički transponovane. Obrazloži svoj stav. Koliko je posmatranje prošlosti i analiza likova i događaja iz detinstva istovremeno i samoposmatranje pripovedača? Argumentuj svoj stav. ${ }^{41}$

Ono u čemu su autori Logosove čitanke na tragu stavova iz Klettove čitanke jeste izgradnja književnog lika župnika i sugestivnosti na kojoj Desnica ovaj lik gradi kao ubedljiv i tipično romaneskni.

No, osnovna razlika u stavovima autora Logosove čitanke jeste proširenje teorijskog polja koje ilustruje Desničin roman. I ovi autori, naime, Proljeća Ivana Galeba uzimaju kao primer za roman-esej, dajući, naravno, modernije teorijsko obrazloženje:

Romaneskno prozno delo protkano filozofskim sadržajima. Stvaralačka forma nastala snažnim prožimanjem umetnosti i filozofije, elemenata romaneskne pripovedne strukture i esejističkih razmišljanja o suštinskim pitanjima ljudske egzistencije i najrazličitijim oblicima umetničkog stvaralaštva. Odličan primer je roman Vladana Desnice Proljeća Ivana Galeba. ${ }^{42}$

41 P. Petrović, M. Đurić, B. Suvajdžić i N. Stanković Šošo, Čitanka za četurti razred, 95.

42 Isto, 95. Objašnjenja teorijskih pojmova autori čitanke su, inače, preuzimali iz Rečnika književnih termina Instituta za književnost i umetnost, te Rečnika književnih termina Tanje Popović. 
Ali, pored ovog teorijskog pojma, Desničin roman poslužio je i kao ilustracija za narativni postupak metafikcije, kao i za pojam antijunaka (primer za to u Proljećima Ivana Galeba je župnik, ali i Ivan, naratorov dvojnik).

\section{$\cos$}

Ova različita, i raznorodna, teorijska i metodološka preispitivanja Desničinog opusa u školskim programima za gimnazije i srednje stručne škole u Srbiji pokazuju da se Desnica iznova utemeljuje kao jedan od književnika čije je ime i delo paradigma kako srpske, tako i hrvatske kulture. Novi metodički i književnoteorijski pristupi, pak, svedoče da je, posle vremena koje je za ovakve pisce, na razmeđi dvaju naroda i dviju kultura bilo sasvim nepovoljno, došlo doba da se Desničinom opusu i u školskim programima i čitankama pristupi odgovorno i kritički, bez ranijih ideoloških učitavanja ili nacionalnih predrasuda i prepucavanja. To će - treba se nadati - i ubuduće biti okvir u kome će Desnicu čitati neke nove generacije srednjoškolaca.

\section{$\cos$}

\section{Vladan Desnica in SERbian school CURricula and TEXTBOOKS}

The work of Vladan Desnica, or more specifically, his novel Proljeća Ivana Galeba (The Springs of Ivan Galeb) has been a part of the Serbian high school curriculum for over half a century. However, over time, the approach to the author and his work has undergone certain changes. Whereas in the time of socialism, within a shared Yugoslav culture, Desnica was mostly studied as a contemporary Croatian author, after the breakup of Yugoslavia, he has been regarded as a contemporary Serbian author. However, the readers and textbooks hardly reflect that change, and Desnica has not received particular attention as a representative of Serbian culture in Croatia.

On the other hand, there have been shifts in the theoretical and methodological approaches to Desnica's work. Originally viewing the work through the lens of modernism, as a novel-essay hybrid, the interpretations of Proljeća Ivana Galeba in readers and textbooks have come to shift their focus to the wider issues of characterization, narration, philosophical tenets and the relationship between art and reality, among many others.

However, the special place Desnica holds in the literary canon is undisputed. He is one of the very few Serbian and Croatian authors who remain on the junction of the language and literature curricula for the final year of secondary school in the Serbian school system. Any examination of Desnica's work, regardless of theoretical and methodological differences, continues to acknowledge that fact.

Key words: Vladan Desnica, The Springs of Ivan Galeb, school curricula, literary history, literary theory, methodology, teaching methods 


\section{Literatura}

Duško BABIĆ, Književnost za četvrti razred srednjih škola, Beograd 2005.

Ljiljana BajIĆ, Miodrag Pavlović i Zona Mrkalj, Čitanka za četurti razred gimnazije i srednjih stručnih škola, Beograd 2016.

Radmilo Dimitrijević i Dimitrije Vučenov, Čitanka za IV razred gimnazije sa teorijom književnosti, 8. izd., Beograd 1967.

Radmilo Dimitrijević i Dimitrije Vučenov, Čitanka za IV razred gimnazije sa teorijom književnosti, 9. izd., Beograd 1969.

Radmilo Dimitrijević i Dimitrije Vučenov, Čitanka za IV razred gimnazije, 10. izd. prilagođeno novom programu, Beograd 1974.

Nastavni plan i program za gimnaziju u Socijalističkoj Republici Srbiji 1964/65, Beograd 1965.

Ljiljana Nikolić i Bosiljka MiLIĆ, Čitanka sa književnoteorijskim pojmovima za IV razred srednje škole, Beograd 1989.

Predrag Petrović, Mina Đurić, Boško Suvajdžıč i Nataša Stanković Šošo, Čitanka za četurti razred gimnazije i srednjih stručnih škola, Beograd 2016.

Petar Pijanović, Književnost i srpski jezik. Udžbenik za četvrti razred gimnazija i srednjih škola, Beograd 2010.

Prosvetni glasnik (Beograd), 15/1965., br. 1-2, 41.

Dragutin Rosandić, Milka CAnıć i Milivoje Minović, Književnost i jezik. Udžbenik za vojne gimnazije i srednje vojne škole, Beograd 1989.

Mario VAldes, „Rethinking the History of Literary History“, Rethinking Literary History: A Dialogueon Theory (ur. Linda Hutcheon i Mario J. Valdes), Oxford - New York 2002., 63-115.

Dragiša Žıvković, Teorija književnosti - Čitanka, Sarajevo 1967. 